\section{Effect of Phenobarbitone}

Q. -What would be the effect of the regular use of, say, 1 gr. (65 mg.) of phenobarbitone soluble a day? Would it have any effect upon a pregnant woman and the child?

A.- In most persons the regular use of $1 \mathrm{gr}$. of soluble phenobarbitone daily would have no ill effect beyond producing a certain heaviness. There is, however, much variation in different individuals, and since it is very slowly excreted it is important to look out for signs of accumulation. Soluble barbitone passes from the maternal blood to the foetus, and, though a dose of $1 \mathrm{gr}$. daily to the mother is certainly small, it ought not to be assumed that if given for many weeks it would have no harmful effect on the baby. The probability that it would do harm is slight, and this must be weighed against the benefit which might accrue to the mother in other directions.

\section{Xerostomia}

Q.-A woman aged 60 has suffered from partial dryness of the mouth for about ten years. For the past four months the dryness has been complete; eating and speaking are now almost impossible. She has a moderate degree of hypertension but a normal blood picture. Dilute hydrochloric acid with meals and large doses of vitamins $A, B, C$, and $D$ have had no effect. What is the cause, and can you suggest treatment?

A.-The description of this patient suggests a diagnosis of Sjögren's syndrome-a condition of unknown cause most frequently seen in elderly women, in which dryness of the mouth and pharynx is associated with keratoconjunctivitis sicca and loss of hair. It would be interesting to know whether there is evidence of the two latter changes in this instance. Treatment is unsatisfactory, both in Sjögren's syndrome and in other types of xerostomia. Large doses of vitamin A $(30,000$ to 40,000 units daily) have been advocated, but it must be admitted that they usually have little effect. It is often necessary for the patient to take a fluid or semi-solid diet, while some of the discomfort can be allayed by frequent mouthwashes.

\section{Stilboestrol and Mastitis in the Male}

Q.-Does stilboestrol cause mastitis in the male? A man aged 73 developed bilateral mastitis after a fortnight's treatment with stilboestrol for prostate trouble. The drug was immediately discontinued, but the condition persists after two months.

A.-Yes, painful enlargement of the breasts is a complication of the stilboestrol treatment for carcinoma of the prostate. The condition usually subsides if treatment is withdrawn. Gynaecomastia also occurs with atrophy of the testes, or with destruction of the liver by cirrhosis or neoplasm. Possibly one or other of these features is present in this case. If the prostatic trouble is non-malignant, testosterone might help the mastitis, but would be contraindicated with carcinoma of the prostate, defeating the object of the original treatment with stilboestrol.

\section{"Semi-hypertrophy"}

Q.-In a female baby aged 5 months the left leg is uniformly fatter, but not longer, than the right. The increase in circumference at mid-calf and mid-thigh is in the neighbourhood of $3 / 4$ to 1 in. (1.9 to $2.5 \mathrm{~cm}$.). The lower half of the body has slightly more fat than the upper half. Radiography shows that the bones and muscles of both sides are equal. The baby has been seen by a paediatrician, an orthopaedic surgeon, and an endocrinologist, none of whom offered any rational explanation or suggestion for treatment.

A.-Various minor degrees of asymmetry of the body are not uncommon, and such a term as "semi-hypertrophy" is used to denote this condition if, as in the case cited, it is at all obvious. It is necessary to exclude any deep-seated naevoid condition; this would be indicated by a warmer feel to the limb and probably some discoloration. In general the differ: ences become less obvious as the child grows. An embryological explanation could possibly be offered; there is no treatment.

\section{NOTES AND COMMENTS}

Intractable Tinnitus.-Mr. N. L. RowE, H.D.D., writes from the Plastic and Jaw Unit, Hill End E.M.S. Hospital, St. Albans, Herts: May I be permitted to make a further observation on the Question and Answer (Jan. 3, p. 34) about "Intractable Tinnitus"? Two factors appear to have been overlooked which may possibly throw some light on the aetiology of the case under discussion. In the first place the presence of unerupted teeth may occasionally give rise to reflex irritation which need not necessarily manifest itself as a neuralgia-as, for example, the occurrence of blepharospasm associated with unerupted maxillary or mandibular third molars. In this case the unerupted upper left canine may, by pressing on the greater palatine nerve, a branch of the spheno-palatine ganglion, be setting up an irritation of the fifth cranial nerve. In this connexion it is worth recalling that the tensor tympani muscle is supplied by the motor division of the trigeminal nerve via the otic ganglion, which itself sends a communicating twig to the nerve of the pterygoid canal on its way to the spheno-palatine ganglion previously mentioned. A communication also exists with the tympanic plexus via the lesser superficial petrosal nerve. I can recall a case of paralysis of the motor division of the trigeminal nerve due to poliomyelitis in which there was tinnitus and impairment of hearing on the same side. In the second place no mention has been made of Costen's syndrome, a term used to denote certain symptoms associated with dysfunction of the temporo-mandibular joint caused by loss of molar support, resulting in the backward displacement of the condylar head on to the tympanic portion of the glenoid fossa (Costen, J. B., Ann. Otol., etc., St. Louis, 1934, 43, 1).

Among such symptoms as trismus, glossodynia, neuralgia, and reflex effects which have been observed tinnitus occupies a prominent place. This has been stated to be due to relaxation of the soft tissues surrounding the Eustachian tube, notably the pterygoideus lateralis and the tensor palati muscles, and although the tube may be pattent; as stated in your correspondent's case, this was presumably upon insufflation and would readily collapse again. Retroposition of the condylar head may cause pressure on the auriculo-temporal branch of the trigeminal nerve, and possibly reflex irritation in this manner, via the otic ganglion, of the nerve to the tensor tympani; or compression of the chorda tympani emerging from the petrotympanic fissure of the glenoid fossa may produce remote effects in its course across the tympanum, although this compression is usually productive of the glossodynia frequently associated with these cases.

Although no indication of the dental condition, apart from freedom from sepsis as shown by radiographic examination, is available in your correspondent's letter, his age (50) is suggestive of the possibility of overclosure of the mandible due to attrition, loss of molar support, or resorption of the alveolar ridges, which amounts to overclosure if a prosthesis is worn. Aggravation of the symptoms upon waking as stated by him can be visualized as due to removal of partial dentures at night, or grinding of the teeth during sleep, with the train of events previously enumerated. At all events, removal of the unerupted canine and investigation into the vertical dimension of the bite would appear to be worth while before designating the condition as "intractable tinnitus."

Thoraco-Lumbar Splanchnicectomy.-Mr. H. A. Haxton (Manchester) writes: I was interested to see (Jan. 10, p. 86) that Mr. F. E. Stock now uses an extended Fey incision in this operation, for I also applied it some 18 months ago. The removal of the lumbar part of the sympathetic chain is easier by this approach than by the usual Smithwick procedure, but there is, in my opinion, a greater risk of tearing the pleura. On the whole, there is little to choose between the two approaches.

\section{Corrections}

In our report of a conference arranged by the National Association for Mental Health (Jan. 24, p. 160) the remarks attributed to "Alderman G. R. Spruit (Hull)" were actually made by Alderman R. E. Smith, who attended as chairman of the Health Committee of Kingston-upon-Hull.

The name of Mr. A. K. Henry was misspelt in the letter from Prof. G. Grey Turner in our issue of Jan. 24 (page 173). All communications with regard to editorial business should be addressed to THE
EDITOR. BRITISH MEDICAL JOURNAL. B.M.A. HOUSE, TAVISTOCK SOUARE, EDITOR, BRITISH MEdicAl Journal. B.M.A. House, TAVISTOCK SQUare, LONDON, W.C.1. TELEPHONE: EUSTON 2111. TELEGRAMSi Aitiology. Westcent. London. ORIGINAL ARTICLES AND LETTERS forwarded for
publication are understood to be offered to the British Medical Journal alone. publication are understood to be offered to the British Medical Journal alone. Authors desiring REPRINTS should communicate with the Publishing B.M.A. House, Tavistock Square, W.C.1, on receipt of proofs. ADVERTISEMENTS should be addressed to the Advertisement Manager,
B.M.A. House, Tavistock Square, London, W.C.1 (hours 9 a.m. to 5 p.m.). B.M.A. House, Tavistock Square, London, W.C.1 (hours 9 a.m. to 5 p.m.). TELEPHONE: EUSTON 2111. TELEGRAMS: Britmedads, Westcent, London. MEMBERS' SUBSCRIPTIONS should be sent to the SECRETARY of the Association. EUSTON, 2111. TELEGRAMS: Medisecra, Westcent, London. B.M.A. SCOTIISH OFFICE: 7, Drumsheugh Gardens, Edinburgh. 